\title{
RESEARCH REGARDING THE SATISFACTION OF BANK SERVICES CONSUMERS AT CEC BANK S.A.
}

\author{
Andreea Muntean ${ }^{1}$ \\ Filimon Stremțan ${ }^{2}$
}

\begin{abstract}
This paper approaches the problems regarding the satisfaction of bank services consumers in the context in which the market concerning these services is characterized by a strong competition between the providers of these services on one hand and by increasing the consumers' demands and expectations on the other hand. The research is meant to measure the satisfaction of consumers of banking services at CEC S.A. Alba. Beforehand there were conducted two exploratory researches, one having as purpose the identification of consumer requirements regarding bank services, aspects which contribute to the formation of their satisfaction, and the other revealing the vision which the bank's management staff has on consumer satisfaction and its importance in maintaining their clients. The results of the selective research led to the conclusion that the majority of the questioned subjects are satisfied and very satisfied with the banking services provided by CEC S.A.
\end{abstract}

Key words: consumer satisfaction, consumer dissatisfaction, expectations, perceived performance, expectations disconfirmation, bank service

JEL Code: $M 31$

\section{Introduction}

Consumer satisfaction is very important for the success of a business because it was demonstrated that it is close related to repurchase, fidelity and profitability. The satisfied consumers are believed to manifest a larger probability to buy that product or service again. Dissatisfied consumers manifest hard feelings towards business, file complaints, they demand their money back and even influence other buyers negatively.

Romania's integration into the European Union had as consequence, among others, the intensification of competition on the markets of various products and services, including the banking services. Achieving the competitive advantage involves offering some quality products and services and customer satisfaction at the highest level. In this respect, many organizations have decided to implement quality management systems complying with the international quality standards. A certified quality management system proves the commitment of a certain company in the delivering quality and satisfying the clients.

ISO 9001:2000 international quality standards place consumers in the center of the quality management system. These standards promote the adoption of a procedural approach in which, through the development, implementation and improvement of a quality management system is pursued the consumer satisfaction by meeting his requests.

Management's role is to make sure that the consumer's requirements are determined and connected with his satisfaction. Management is also responsible for making available the adequate resources so that the organization can develop and provide the product or service. In order to assess the success of the organization in achieving this objective, consumer satisfaction should be

\footnotetext{
${ }^{1} 1$ Decembrie 1918 University of Alba Iulia, e-mail: munteanandreea2009@yahoo.com

21 Decembrie 1918 University of Alba Iulia, e-mail: filimon_stremtan@yahoo.com 
measured and the results should be used as key elements to continuously improve the quality management system.

Romania's banking sector faces the same challenges. Increased competition between banks and increased requirements of the customers has led to a change in the attitude of those operating on this market. Banks become more and more concerned with improving the quality of services and satisfaction of own customers. In this respect, the design and implementation of some systematic programs to trace and improve the satisfaction of the banking services consumer is needed. The present study aims at providing a theoretical and methodological framework for achieving such an approach.

\section{Literature Review}

The first scientific research approaching consumer satisfaction appeared in the late 60's, slowly expanding until present when the interest in this field of research has increased, a proof being the numerous organizations, publications and researches dedicated to it. In the period involving the 70's, the research regarding consumer satisfaction/dissatisfaction can be divided into two categories: researches that pursue the outlining of satisfaction incidents for different products and services, and experimental researches meant for assessing the expectations' impact regarding product performance on post-consumption satisfaction or on perceived performance. In the early 80 's, the entire research work concerning consumer satisfaction at a theoretic and empiric level was centered on the so-called "expectations disconfirmation paradigm". According to this model, for which Richard Oliver has brought an important contribution, the satisfaction/dissatisfaction represents a function of consumer's expectations regarding the performances of the product, the performance given by the product and of the comparison made between the expectations before and after buying the product. In the early 90's, companies manifested a large interest in the results of the studies regarding consumer satisfaction. Between 1982 and 1992, over 900 articles having as a theme the consumer satisfaction, dissatisfaction and complaining behavior were published.

In the last decade, researchers' attention was drawn towards determinants and their consequences, towards exploration of new comparison standards in the process of disconfirmation and last but not least towards the attempts of modeling the formation process of satisfaction both at macro and micro economical level.

Concerning the definition of the concept, even if in the specialty literature there are numerous and different definitions of consumer satisfaction, they have in common three elements: (1) consumer satisfaction is an emotional or cognitive response; (2) the response is focused on expectations, on product, on consumption experience, etc.; (3) the response manifests at a certain time (after consumption, after selection, based on an experience accumulated in time, etc.).

In presenting the concept of consumers satisfaction one must consider the role of affection in its formation and the differences that exist between service quality evaluation and satisfaction regarding this service.

Expectations, disconfirmation and perceived performance can be considered the determinant factors of consumer satisfaction. The consequences of consumers satisfaction refers to its implications on the bank's economic and social efficiency and to consumer's response to satisfaction/dissatisfaction.

An important role in consumer satisfaction research is given to organizing the methodology of such a process. The essential thing in measuring consumer's satisfaction is represented by an organization of some exploratory researches in order to identify the basic aspects taken into consideration by the consumers when they declare themselves satisfied or dissatisfied with a banking service. In order to identify consumers' requirements regarding a banking service more techniques can be used, the most frequently used being discussion groups, consumers' visits and critical incidents technique. For gathering information regarding consumer's satisfaction with a bank service one might resort to classic surveys, computer assisted surveys and on-line surveys. 
The questionnaire's design, as an instrument of collecting data on satisfaction begins from the consumer's requirements identified through exploratory researches. The types of scales used in the questionnaire as instruments for measuring consumer's satisfaction may be verbal, numerical or pictorial, each type having its own supporters and opponents. Assessing the reliability and validity of this process has an exquisite importance in measuring consumer's satisfaction.

The success of a research programme on consumer's satisfaction depends not only on the survey's design or on the method or way of collecting the data, but on the researcher's competence and skill to analyze the data collected. From the multitude of analysis methods that the researcher has, he will choose the ones that best correspond to the objectives of the research.

\section{Methodology Research}

The qualitative research, having an exploratory character and being previously conducted paved the way for the development of the research having a descriptive role. The purpose of this research was represented by the measurement of the satisfaction of bank services consumers at CEC S.A. Alba.

Closely related to the purpose of the research and given the consumers' requirements determined in the exploratory stage, the following primary and secondary objectives were defined: (1) measuring the satisfaction of consumers in relation with the information received from the bank's staff, with the courtesy of the bank's staff, with the patience of the bank's staff, with the availability of the Bank's staff, with the efficiency of the bank's staff, with understanding the customer's needs by the bank's staff, with the professionalism of the bank's staff with the diversity of services provided by the bank, with the size of the interests charged by the bank, with the size of bank's commissions, with the atmosphere from the bank, (2) Measuring the overall satisfaction of consumers with the bank's services according to their age, their socio-professional category, the monthly income of their family, their area of origin, their sex, (3) identifying the intentions to repurchase the bank's services.

The main hypotheses of the research were formulated as follows:

H0: there are no significant differences between the medium levels of the overall satisfaction of consumers belonging to different age groups;

H0: there are no significant differences between the medium levels of the overall satisfaction of consumers belonging to different socio-professional groups;

H0: there are no significant differences between the medium levels of the overall satisfaction of consumers belonging to different categories of monthly income per family.

For collecting the data regarding satisfaction, a selective research among the bank's clients from Alba Iulia was conducted on a sample of 338 persons, using a questionnaire made of 21 questions. 14 main objectives were established from the purpose of the research, and several secondary objectives, derived from the main ones based on 5 socio-economic and demographic criteria. There were established 17 research hypothesis and 16 variables starting from the formulated objectives and from the specific of the investigated theme.

\section{Results}

The analysis of variation was a valuable starting point in exploring the nature of the results regarding the satisfaction of banking services consumers at CEC S.A. Thus, was paved the way for the application of some complex statistical analysis methods.

In analyzing the variation of variables measured within the research, we resorted to frequencies distribution. According to the results, most of the question subjects are satisfied with the information receive from the bank's staff about different products or services. Those who declared themselves very satisfied with this aspect are 172 persons representing $50,9 \%$ of the total sample. Only $0,6 \%$ of the respondents were dissatisfied with the information received from the bank's staff. No one said he was very dissatisfied. About the courtesy of the bank's staff, 36,7\% of 
the investigated subjects said they are satisfied with this aspect and 57,4\% of them said they are very satisfied. A number of 126 questioned subjects, representing 37,3\% of the total sample said they were satisfied with the patience shown by the bank's staff. Most of the investigated subjects, respectively $47 \%$ from the total sample were very satisfied in terms of staff's availability. The majority of the respondents, respectively $49,7 \%$ from the total sample were very satisfied with the staff's efficiency. A number of 155 respondents $(45,9 \%)$ were very satisfied with the staff understanding their needs and 39.9\% of them were satisfied. Most respondents, respectively $91,4 \%$ were satisfied and very satisfied with the staff's professionalism and only $2,1 \%$ were dissatisfied and very dissatisfied. The majority of the respondents $(39,6 \%)$ are satisfied with the diversity of bank's services and $21 \%$ of the total sample are very satisfied with this aspect; dissatisfied were 20 respondents representing 5,9\% of the investigated sample. 50\% of the investigated subjects (169 persons) were neither satisfied, nor dissatisfied with the level of interest charged by the bank. Related to this aspect of the services provided by CEC S.A. the number of dissatisfied and very dissatisfied persons is much higher than in the previous cases, amounting to 65 persons, i.e. almost $20 \%$ of the investigated sample; the investigates subjects who said they are very satisfied with the size of the interests represent $7,7 \%$ from the total sample. In relation to the commissions charged by the bank for different operations, most of the respondents, i.e. 51,5\% of the total sample were neither satisfied, nor dissatisfied. More than half of the investigated subjects are very satisfied and satisfied with the atmosphere from the bank (51,5\% of the investigated sample) and almost $40 \%$ of the total are satisfied with this aspect.

Overall, almost half of the respondents, respectively $49,7 \%$ of the total investigated sample are satisfied with the bank's services. Very satisfied are 132 investigated subjects, representing $39,1 \%$ of the total. Neither satisfied, nor dissatisfied are $10,9 \%$ of the respondents. Only one person was dissatisfied with the overall services of the bank and no respondent was very dissatisfied.

In terms of the intentions of repurchasing the bank's products and services most of the respondents $(30,2 \%$ of the sample, respectively 102 persons) have expressed their intentions to return to the bank $100 \%$.

The question arising is whether there are indeed significant differences statistically speaking between the satisfaction level of different consumer groups. In order to answer this question was used the variance analysis. Applying the method involved two successive phases. First, the level of significance $(p)$ for test $\mathrm{F}$ was determined. If its value is less than 0,05 it means that there is at least a significant difference between the satisfaction averages of two consumers groups. Later, one may resort to one of several statistical tests (named, in the specialty literature, "post hoc" tests) in order to determine how many significant differences are there and also what are the differences. In the present research, Duncan test was used.

Null hypothesis initially formulated and the results obtained as a consequence of applying the variance analysis are presented below.

The first null hypothesis being tested and the corresponding alternative hypothesis are the following:

H0: there are no significant differences between the medium levels of the overall satisfaction of consumers belonging to different age groups.

H1: there are significant differences between the medium levels of the overall satisfaction of consumers belonging to different age groups.

Applying the analysis method led to obtaining a significance level for test $\mathrm{F}$ of 0,000 whose value is less than 0,05 which means that there is at least one significant difference between the two groups. After applying the Duncan test, using SPSS package were generated the following results: 
Table no. 1.

The results of Duncan test

\begin{tabular}{|l|r|c|c|}
\hline Age category & Frequencies & \multicolumn{2}{|c|}{ Groups } \\
\cline { 3 - 4 } & & $\mathbf{1}$ & $\mathbf{2}$ \\
\hline 31-40 years & 76 & 4.0395 & \\
\hline 41-50 years & 64 & 4.1250 & \\
\hline 18-22 years & 21 & 4.1429 & \\
\hline 23-30 years & 27 & 4.2222 & \\
\hline 51-60 years & 59 & 4.2542 & \\
\hline over 60 years & 91 & & 4.6374 \\
\hline
\end{tabular}

In the table, data is arranged in descending order of the medium levels of the overall satisfaction from left to right. The results of this test clarify the information on the differences between groups. As it can be seen, there are some significant differences between the medium level of overall satisfaction of the people over 60 and the average of overall satisfaction for the other age categories.

In conclusion, the alternative hypothesis $\mathrm{H} 1$ is accepted. following:

The second null hypothesis to be tested and the corresponding alternative hypothesis are the

H0: there are no significant differences between the medium levels of the overall satisfaction of consumers belonging to different socio-professional groups

H1: there are significant differences between the medium levels of the overall satisfaction of consumers belonging to different socio-professional groups

The level of significance obtained for test $F$ was 0,000 smaller than 0,05 which means there is a significant difference between the averages of the overall satisfaction of at least two groups. The results of Duncan tests are the following:

Table no. 2 .

The results of Duncan test

\begin{tabular}{|l|r|r|c|}
\hline \multicolumn{1}{|c|}{ Socio-professional category } & \multirow{2}{*}{ Groups } \\
\cline { 3 - 4 } & Frequencies & $\mathbf{1}$ & $\mathbf{2}$ \\
\hline Persons with academic studies & 55 & 3.9273 & \\
& & 4.0000 & \\
\hline Pupil & 28 & 4.0000 & \\
\hline Private entrepreneur & 41 & 4.1707 & \\
\hline Office worker & 25 & 4.2000 & \\
\hline Student & 49 & 4.2245 & \\
\hline Worker & 3 & 4.3333 & \\
\hline Stay-at-home persons & 7 & 4.4286 & \\
\hline Other & 126 & & 4.5556 \\
\hline Pensioners & & & \\
\hline
\end{tabular}

From how the data is grouped in the table can be inferred that there is a significant difference between the medium level of the overall satisfaction of the category of pensioners and the other socio-professional categories.

In conclusion, the alternative hypothesis $\mathrm{H} 1$ is accepted. 

following:

The third hypothesis to be tested and the corresponding alternative hypothesis are the

HO: there are no significant differences between the medium levels of the overall satisfaction of consumers belonging to different categories of monthly income per family

H1: there are significant differences between the medium levels of the overall satisfaction of consumers belonging to different categories of monthly income per family

The level of significance obtained for test $\mathrm{F}$ is equal to 0,078 which is more than 0,05 . Therefore there are not two groups for which the medium level of the overall satisfaction differs significantly. In conclusion, the null hypothesis $\mathrm{HO}$ is accepted.

The analysis of variation shows that there are significant differences between the medium levels of the overall satisfaction of persons over 60 years old and the averages of the overall satisfaction for other age categories, and also between pensioners and other socio-professional categories. In conclusion, in order to increase the medium level of satisfying its customers, the bank should seek to improve the satisfaction of consumers over 60 years old, belonging to other socioprofessional categories besides pensioners. First, it is recommended to identify the aspects regarding the banking services which mostly influence satisfaction among these categories of consumers.

\section{Conclusions}

The results of the selective research led to the conclusion that the majority of the questioned subjects are satisfied and very satisfied with the banking services provided by CEC S.A. The medium level of the overall satisfaction regarding the bank's services was 4.27, pointing out that the services provided by the bank manage to supply a relatively high level of satisfaction for its clients.

The closest correlations were determined between the overall satisfaction and the satisfaction concerning the staff's professionalism, concerning the information received from the bank's staff and concerning the understanding of the costumer's needs. The variation analysis demonstrates that there are significant differences in the medium levels of the overall satisfaction between people over 60 years old and other age categories, as well as between the medium levels of the overall satisfaction of the pensioners and other socio-professional categories. The satisfaction of bank services consumers has a positive impact on the bank's social and economic efficiency.

Finally, we can conclude that by having a theoretical and methodological base the banks can initiate and implement systematic programs of measuring their consumers' satisfaction whose results would be used for improving the satisfaction level. In time, their efforts will materialize and we will witness an increase in the bank's social and economic efficiency.

\section{References}

1. Cătoiu I. (Coord), 2009. Cercetări de marketing - Treaty, Uranus Publishing House, Bucharest

2. Cătoiu, I., Teodorescu, N., 2004. Comportamentul consumatorului, ediția a II-a, Editura Uranus, Bucureşti

4. Giese J.L., Cote J.A., 2002. Defining Consumer Satisfaction, Academy of Marketing Science Review, vol. 1

5. Hayes B.E., 1997. Measuring Customer Satisfaction - Survey Design, Use and Statistical Analysis Methods, ASQ Quality Press, Wisconsin

6. Hotchkiss J.H., 1992. Pesticide residue controls to ensure food safety. Critical Reviews in Food Science and Nutrition. 31(3), pp. 191-203 
7. Ippolito P.M., Mathios A.D., 1989. Health claims in labelling and advertising, a study of the cereal market. Washington, DC, United States Federal Trade Commission

8. Jay J.M., 1992. Microbiological food safety, Critical Reviews in Food Science and Nutrition, 31 (3), pp. 177-190

9. Labuza T.P, Basier W., 1992. The role of the Federal Government in food safety. Critical Reviews in Food Science and Nutrition, 31 (3), pp. 165-176

3. McCullough F., Jones S., Vignali D., 2003. The pot snack market - are today's consumers demanding health as well as convenience?, British Food Journal, Vol. 105 Iss: 6, pp.395 404

10. Moonkyu L., Ulgado F. M., 1997. Consumer evaluations of fast-food services: a crossnational comparison, Journal of Services Marketing, Vol. 11, Issue 1, pp.39 - 52

11. Muntean A., Satisfacția consumatorilor de servicii bancare, Editura Casa Cărții de Ştiință, Cluj Napoca, 2010

11. Oliver R., 1997. Satisfaction: A Behavioral Perspective on the Consumer, The McGraw-Hill Companies, Inc. New York

12. Yi Y., 1990. A Critical Review Of Consumer Satisfaction, Review of Marketing, American Marketing Association, Chicago

18. Bolog (Muntean) A., Cercetarea satisfacíei de servicii bancare şi implicațiile acesteia asupra eficienţei economice şi sociale a băncii, Doctoral thesis, available online at http://www.biblioteca.ase.ro/resurse/resurse_electronice/teze.php 